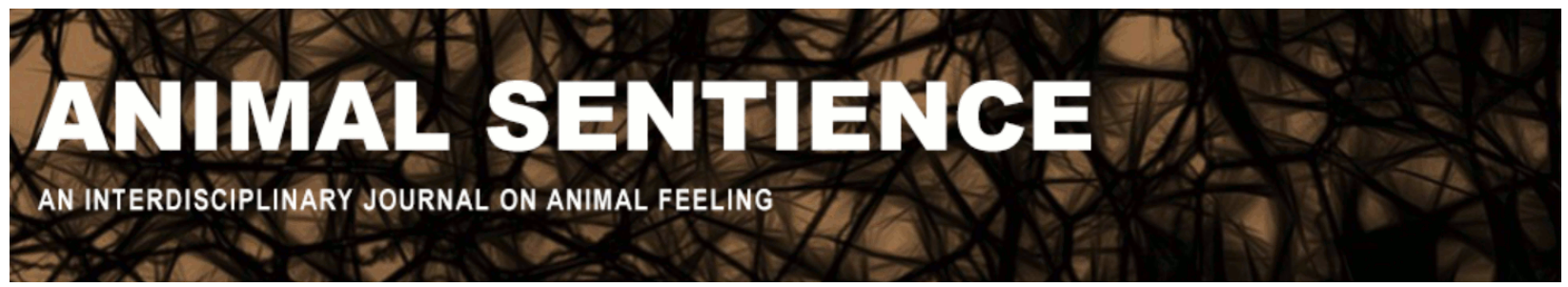

Hadley, John (2018) Post-Darwin skepticism and run-of-the-mill suicide. Animal Sentience 20(11)

DOI: $10.51291 / 2377-7478.1299$

Date of submission: 2018-01-18

Date of acceptance: 2018-01-23

(c) 


\title{
Post-Darwin skepticism and run-of-the-mill suicide
}

Commentary on Peña-Guzmán on Animal Suicide

\author{
John Hadley \\ School of Humanities and Communication Arts \\ Western Sydney University
}

\begin{abstract}
Peña-Guzmán's depiction of the opponent of animal suicide as a conservative is a straw man. It is possible to accept that animals are self-conscious and reflexive yet still reject the view that they have the mental wherewithal to commit run-of-the-mill suicide. That animal behaviour can be positioned on a continuum of self-destructive behaviour does not establish that animals can intentionally kill themselves.
\end{abstract}

\begin{abstract}
John Hadley, senior lecturer in philosophy, Western Sydney University, has published on a wide range of topics in animal ethics and political theory. Animal Property Rights: A Theory of Habitat Rights for Wild Animals (Lexington 2015) explores the theoretical and practical challenges of extending liberal property rights theory to nonhuman animals. www.westernsydney.edu.au/staff profiles/uws profiles/doctor_john_hadley
\end{abstract}

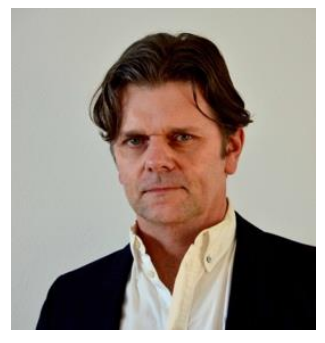

Peña-Guzmán (2017) misrepresents the position of the skeptic. One need not believe that reflexivity is an all-or-nothing capacity, nor that reflexivity maps neatly onto species classification, in order to reject the view that nonhuman animals (hereafter, animals) can commit suicide. Instead, the skeptic can coherently hold that reflexivity admits of degrees and that some humans, such as newborn infants and people with severe cognitive impairment, may lack reflexivity. In other words, a skeptic can hold that animals are subjectively reflexive but nonetheless still lack the requisite mental wherewithal to satisfy the conditions for run-of-the-mill suicide. ${ }^{1}$ Believing as much does not make one a speciesist, a Cartesian or an anthropocentric conservative.

I say "run-of-the-mill" suicide because, as Peña-Guzmán intimates (p. 2), suicide is a complex phenomenon and care needs to be taken to distinguish actions that may directly or indirectly diminish well-being from the act of intentionally taking one's life. A living being does not have to be all that psychologically complex in order to behave in ways that we may judge as detrimental to well-being. Think of infants who will put anything and everything into their mouths. I presuppose that to take one's life, in the relevant sense for a discussion of animal suicide, is for an individual to do so under conditions of anguish - after making a judgment that one's life is not worth living. ${ }^{2}$ It is the wherewithal for making such a judgment, in the absence of compelling empirical evidence to the contrary (Preti 2007), that it is reasonable to believe animals lack.

\footnotetext{
${ }^{1}$ I borrow the expression "run-of-the-mill" suicide from Cholbi (2017).

${ }^{2}$ While suicide bombers and kamikaze pilots knowingly lose their lives, they do not take their own lives in the relevant sense because their actions are not attendant upon a judgment that life is not worth living. For the purposes of this paper, suicide bombers and kamikaze pilots are not run-of-the-mill cases.
} 
To be able to judge that life is not worth living requires more than self-conscious reflexivity but the possession of mental states with specific content, and the capacity for making comparative judgments about life and its prospects. After all, self-conscious reflexivity may entail only bodily awareness, as opposed to awareness of oneself as a subject of continuing experiences (DeGrazia 2009, p. 201), or just the ability to read the mind of conspecifics (Hare, et al. 2000). Nothing about the ability to judge one's future prospects under conditions of anguish can be read off either capacity. Of course, reflective judgments do not have to take the form of sentence-like structures (Rescorla 2009), but they presumably do need to have content (Carruthers 2000; Fodor 1974; Stich 1979). ${ }^{3}$ The proponent of animal suicide needs to give evidence that animals have mental states with the requisite content. Peña-Guzmán gives reasonable grounds for thinking that animals have the concept of death (pp. 6-7). He wants us to go on to accept that the remaining mental wherewithal can be inferred from evidence that animals experience negative emotions, engage in self-injurious and self-destructive behaviours, and (for some species such as dolphins and primates) pass mirror recognition tests. One can accept all of these facts yet still not be convinced that animals have what it takes to intentionally kill themselves after judging that their lives are not worth living.

Peña-Guzmán may argue that it was never his intention to suggest that animals can commit run-of-the-mill suicide and that all he was seeking to do was to make the case for thinking that "self-destructive and self-injurious behaviour among human and nonhuman animals vary on a continuum" (p. 1). But if that is the case, then his project would lack serious philosophical interest. Since Darwin, it can be accepted as a trivial truth that the psychology of humans and animals is different only by degree and not kind. What the post-Darwin skeptic wants to see is grounds for thinking that certain animal behaviours warrant a place on the continuum beyond the threshold marking behaviour that leads to the act of taking one's life. Consider an analogy with moral responsibility. Children, adolescents and dementia patients are all capable of performing the kinds of actions that ordinarily only persons are held responsible for; punching, biting, being rude and obnoxious, etcetera. ${ }^{4}$ Nevertheless, being able to perform such actions is arguably sufficient for placing children, adolescents and dementia patients on the moral responsibility continuum. But, that children, adolescents and dementia patients warrant a place on the continuum because they can perform actions that ordinarily only persons are held responsible for, does not tell us whether they should be counted among the genuinely morally responsible. What we require is grounds for thinking that this or that individual has the requisite mental states to be held accountable for their actions. Likewise, with any suicide continuum: that animals may occupy a place on it does not establish that they can commit run-of-the-mill suicide.

\footnotetext{
${ }^{3}$ For simplicity, I leave aside the issue of whether the mental states must be explicable in terms of beliefs and desires, and the related question of whether the content is conceptual or nonconceptual.

${ }^{4}$ By "person" I mean so-called mentally competent adults and, in some circumstances, young people who may be sufficiently informed in virtue of possessing the relevant concepts. Logically, as recent attempts to establish legal standing for great apes and cetaceans attest (Wise 2002), the class of persons need not be restricted to a sub-set of the species Homo sapiens.
} 


\section{References}

Carrruthers, P. (2004). Consciousness: Essays from a higher order perspective. Oxford: Oxford University Press.

Cholbi, M. (2017). Suicide. The Stanford encyclopedia of philosophy (Fall 2017 Edition). ed. E.N. Zalta.

DeGrazia, D. (2009). Self-awareness in animals. In The philosophy of animal minds, ed. R.W. Lurz, 201-217. Cambridge: Cambridge University Press.

Fodor, J. (1975). Language of thought. Cambridge, MA: Harvard University Press.

Hare, B. (2000). Chimpanzees know what conspecifics do and do not see. Animal Behaviour, $59,771-85$.

Peña-Guzmán, D.M. (2017). Can nonhuman animals commit suicide? Animal Sentience 20(1).

Preti, A. (2007). Suicide among animals: A review of the evidence. Psychological Reports, 101, 831-48.

Rescorla, M. (2009). Chrisippus' dog as a case study in non-linguistic cognition. In The philosophy of animal minds, ed. R.W. Lurz, 52-71. Cambridge: Cambridge University Press.

Stich, S. (1979). Do animals have beliefs? Australasian Journal of Philosophy, 57, 15-28.

Wise, S.M. (2002). Drawing the line: Science and the case for animal rights. Cambridge, MA: Perseus Books. 